\title{
Mr Justice Parker and technical fact
}

Mr Justice Parker, who some time ago handled the Flixborough inquiry into a devastating explosion in a British chemical plant with consummate judicial skill, applied the same talents last year to the proposed construction of THORP (see p298). He was appointed to the Windscale Inquiry, as it became known, perhaps because he had gained experience at Flixborough in inquiries requiring assessment of technical argument.

Therefore, as one might expect, where the arguments concerning the construction of THORP are capable of strict technical analysis Justice Parker's final report - published by the government on 6 March this year - is masterly. At the lowest level of contention, his description of the basic physics and chemistry of the nuclear fuel cycle should be read by anyone wishing to understand the technical basis of nuclear power and the reprocessing of nuclear fuel.

At the next level, Justice Parker's chapters on risk perform a very valuable function in drawing together the data on the effects of routine discharges of radionuclides from Windscale, and on assessing the possibilities of accident. The Inspector even ordered a few experiments. With their agreement he subjected a few regular fish eaters on the coast (where the existing Magnox reprocessing facility discharges low-level liquid waste) to whole body monitoring for the presence of radioactive elements passed down the food chain to the fish and thence to the fish eater. Levels were well below the limits set by the International Commission on Radiological Protection. In such ways $\mathrm{Mr}$ Justice Parker allayed some fears about the dangers of Windscale by ascertaining facts.

Parker has also made some positive recommendations for improvement, as in the scientific competence of the Nuclear Installations Inspectorate (NII) to check the designs of THORP were it to be built, and in the constitution of the Windscale local liaison committee. The latter was set up to prepare emergency plans between the local community and Windscale, but, writes the Inspector 'it emerged in evidence that some of those who, in the event of an emergency, would be required to take action under the plan ... did not even know they had any responsibilities, much less know what these responsibilities were. This was clearly a grave defect ... British Nuclear Fuels Ltd (BNFL) who control Windscale have agreed to act on all Parker's criticisms so local liaison at least should improve shortly.

Politics is involved in the environmental and health risks associated with THORP at least to the extent that being subject to them is not a matter of choice for the local residents; but it seems clear that the risks are not likely to be greater than those involved with any other industry.

But in almost all the other issues faced by the Inspector complex political judgements are involved. The two central political questions concerned with the construction of THORP are international and national: the effect on the proliferation of nuclear weapons (which we deal with on $\mathrm{p} 302$ ), and the choice of UK energy future. The latter choice offers a number of options quite distinct from the familiar ones of the high growth and low growth future. On one of these Mr Justice Parker heard two days of evidence (outlined below) from Gerald Leach of

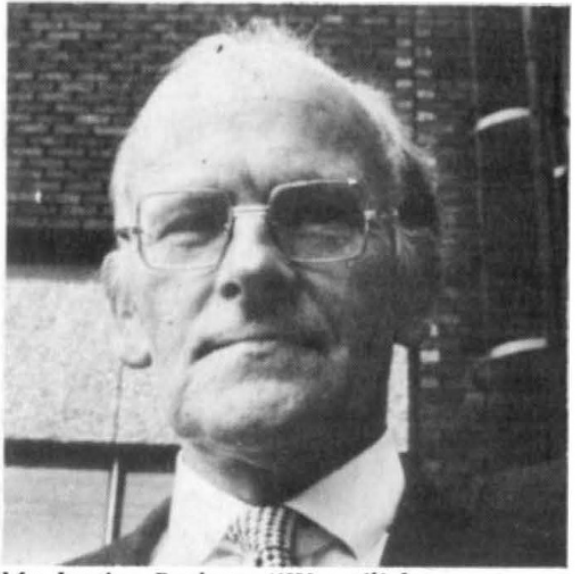

Mr Justice Parker:: "We will be castigated anyway"

the International Institute for Environment and Development (IILD), but he pays scant attention to this in his report.

The choice of energy future (in Leach's paper it is one of low primary energy reached largely by choice of efficient consumption technology) drastically affects Mr Justice Parker's recommendation to build IHORP.

$\mathrm{He}$ argues in his conclusions that: first, extra facilities are needed for projected UK arisings of spent fuel after about 1995; second, the best way of dealing with the wastes is to reprocess the fuel; third, that it is better to build the plant early rather than late to gain experience of the technology and avoid possible technical hitches; and fourth, that if we are going to have reprocessing anyway we might as well improve its economics by importing foreign fuel for treatment. (He disposes of the problem of the proliferation of nuclear weapons on the way by a special reading of the non-proliferation treaty.)

Thus the argument depends on the projected UK arisings, which have their origins in a forecast of the Central Electricity Generating Board. This in turn depends on an energy consumption forecast. A forecast used in this way represents a political decision. It sclects a particular path among many options. Parker's words in the report are illuminating. Considering UK arisings of spent fuel to the year 2000 he first calculates that 4,150 tonnes will have arisen from existing reactors and from those under construction. He goes on "If, as appears likely, reactors to produce a further $4,000 \mathrm{MW}$ per year of electricity are ordered in the near future and begin to operate between 1990 and 1995 they will, by the year 2000 , have produced a further 1,700 tonnes of spent fuel. Thus a total of 6,000 tonnes by the year 2000 from UK reactors alone is a realistic forecast". (Another $4,000 \mathrm{MW}$ is a large increase in nuclear power: the total nuclear generating capacity in England and Wales at the end of March last year was $3,462 \mathrm{MW}$ ).

It quite genuinely seems not to have occurred to Mr Parker, that the use of "as appears likely" and "realistic" is, intentionally or not, loaded, representing a choice of paths among alternatives. For example, the Department of Energy's recent decision to invest in the conservation of energy is projected by the department to reduce energy consumption by the end of the centry by $20 \%$ - or the equivalent of about $40,000 \mathrm{MW}$. Flexibilities of that order by political choice are quite feasible.

\section{Energy futures}

Gerald Leach's two days of evidence, which formed an interim report on a study to be published by IIED in June, described a future with "substantial rises in material standards, mobility and other energy-related activities". But it required not a rise but a reduction primary energy demand by the year 2000. This is achieved through increased consumption efficiencies with, for example, gas-fired heat pumps for heating and good thermal insulation. The energy group of the Sussex University Science Policy Research Unit has also discovered that market competition between North Sea gas and electricity at the end of the century might restrict elcctricity to "essential" uses --such as lights, television, and electric motors. It follows, because of the poor energy efficiency of electricity generation in power stations, that on this basis there is a reduction of some $40 \%$ in primary energy consumption.

Futures studies have lately taken on a completely new meaning, of which Mr Justice Parker does not appear to be aware: the meaning of offering an option to a policy maker, not of predicting the future. $\mathrm{Mr}$ Wedgwood Benn, the UK Secretary of State for Fnergy, expressed a view on this at a meeting on Windscale at the Royal Institution last year: "To be mes- 
merised by forecasts is a way of getting you to do what the forecaster wants you to do" said Benn. "I want to have elbow room". Elbow room-in the form of a set of decision options and their probable consequences-is what energy forecasts are now offering; it is false thinking to take only one as "realistic".

Mr Justice Parker uses his single set of projected arisings to indicate that the existing Windscale reprocessing facilities, and those already granted planning permission, are insufficient to cope with the load.

\section{Waste management}

The next step is to show that the only effective means of dealing with this excess of spent fuel is to reprocess it-that is, to treat it chemically to separate out the highly active wastes and, as a by-product of the existing process, produce separated uranium and plutonium. (The latter is not an essential step in that it can be reversed to produce a degraded mixture of the two, but it is essential if it is wished to conserve plutonium for bombs or fast breeder reactors).

Here again a political element creeps in. The inquiry considered two principal options. The first is as proposed for THORP, to reprocess spent fuel rods, separate out the highly active wastes containing fission products and actinides, glassify the result and dispose of it underground in geologically stable rock formations. The second is to hold the spent fuel in its can, perhaps further encapsulate it, and store it in cooling ponds or in dry vaults (possibly filled with inert gas).

Each means of waste management suffers an unresolved technical problem. In the reprocessing route, we do not know if geological storage will work for the 100,000 years or so for which the actinides are decaying. If it failed, a large amount of radioactivity could be released upon future generations. Equally in the storage route we do not know if the cans (stainless steel in the case of AGR reactors and zirconium alloy in the case of PWRs) will corrode.

Agreed scientific knowledge is lacking in both cases; and projecting the futures of materials must always be contentious as the only conclusive way to test a theory is to wait and see. Effective work on both has only recently been undertaken. What research there has been has concentrated on the reprocessing route, as reprocessing has always been the objective of the nuclear industry for a reason other than waste management: the separation of plutonium.

So it is difficult, if not impossible, to assess in an entirely objective way which is the most effective means of waste management. In such cases an apparently scientific and technical choice is in reality influenced by other forces: particularly, consideration of the decision one wants to reach. In that sense the choice becomes a matter for political debate. Mr Justice Parker's choice (glassification) appeared to rest on his confidence in BNFL, hardly an impartial observer.

\section{Proliferation}

The most difficult political judgement in the report concerns the proliferation of nuclear weapons through the separation of plutonium in reprocessing. (In Japan's contract with BNFL, for example, plutonium-and the wastes-ultimately return to Japan, if the US, supplier of the original uranium, is willing.) If energy futures studies and waste management options offer a political choice, the dangers of proliferation require a finely balanced international diplomatic and political perspective, and should surely not have been a matter for decision in a court in Cumbria. BNFL's argument that providing reprocessing facilities, under international control, for foreign countries was deproliferating in that it discouraged those countries from developing their own unsafeguarded reprocessing plants was accepted by Mr Justice Parker.

Yet he did not apply to those countries the argument he applied to the UK: that there was pressure to reprocess to lessen dependence on foreign suppliers through the collection of plutonium (which might give a 50 fold increase in the available energy in a given stock of uranium, if fast breeder reactors were employed).

Nor did Parker give weight to the over-riding question in proliferation: the effect that the example of buildTHORP might have on the tense international atmosphere prevailing on commercial trading in nuclear materials.

$\mathrm{Mr}$ Justice Parker accepted the arguments of BNFL and yet BNFL's strict impartiality on proliferation must be questioned. It is true that many people in the nuclear industry have been involved in international exercises on non-proliferation throughout their careers; but they have inevitably mixed motives.

Their aim is to transfer nuclear technology and materials; but with that goes a small but unavoidable risk of bringing another country closer to nuclear war-a risk they attempt to reduce. One way of reducing the risk (in the short term at least, before the country creates its own technology) is not to transfer the technology or materials at all. But that option would not be likely to occur to them. The attitude of certain senior members of BNFL to proliferation is, to say the least, equivocal: in an interview with Nature last week one made it plain that in his view limited nuclear war in remote countries using weapons made from commercial-grade plutonium need not necessarily escalate to global conflict and would be survivable even for the countries involved.

It is with this kind of pressurewhether those producing it were aware of it or not-that $\mathrm{Mr}$ Justice Parker was dealing; yet he shows no signs of recognising the fact in his report, and perhaps compensating for it.

Mr Justice Parker, however, is not to be castigated for coming to decisions on all these issues. That was his role: as a judge, to judge. But while demonstrating the ridiculousness of many of the more irrational fears about nuclear power-a good thing - he did little to illuminate the corners where the political decision making lay.

The Inquiry itself, however, had done just that, and many had been left with a hope-which in retrospect seems no more than romantic -that the report would reflect the debate. But $\mathrm{Mr}$ Justice Parker was there to decide, not to illuminate controversy.

Yet it might still be the case that the kind of analysis given here of the political content of technical decision making would be alien to him. Introduced by politically leftist thinkers and groups it seems automatically to have been ignored by those of a rightist inclination-because of its unsavoury associations. But the decisions would still have a political content even if $\mathrm{Mr}$ Justice Parker had decided in completely the opposite direction, and this article would have equal force. It is the nature of the case. Technical decisions as complex as these have a political content and that content must be isolated and recognised for what it is.

It is illuminating to discover that, with a few outstanding exceptions, those to whom the political content of the report has become apparent are those who disagree with its conclusion. Sir John Hill, chairman of the United Kingdom Atomic Energy Authority, is delighted with the report for its "lack of ambivalence. I'm not fond of debate" said Sir John "I prefer analysis". Sir John considered the document to be preferable to its forerunner on nuclear power, the sixth report of the Royal Commission on Environmental Pollution, chaired by Sir Brian Flowers, which he did find to be ambivalent. But this indeed was its strength, in that it declared the places where there must be political decisions and proffered the evidence. Mr Justice Parker, if the constitution of the inquiry had allowed it, would have done better to have done the same.

Robert Walgate 